\title{
RETHINKING THE POTENCY OF ICAO SARPS ON GLOBAL REDUCTION OF AVIATION EMISSION AND PROTECTION OF GLOBAL ENVIRONMENT
}

\author{
Murtala Ganiyu A Murgan, Abdul Ghafur Hamid, Maizatun Mustapha \\ University of Ilorin, Faculty of Law \\ International Islamic University, Ahmad Ibrahim Kulliyyah of Laws
}

\begin{abstract}
The Standards and Recommended Practices (SARPs) of Annex 16 Vol. II, Chicago Convention 1944, are created and adopted by the International Civil Aviation Organization (ICAO), for the purpose of regulating aircraft emission in the civil aviation sector. The creation of ICAO standard and Recommended Practices on aviation environment came up in 1981, following the declaration in Article 2(2) ${ }^{1}$ of Kyoto protocol to UNFCCC that developed countries of (Annex I parties), shall pursue limitation or reduction of emission of greenhouse gases from aviation by working through the international civil aviation organization (ICAO). However, while the SARPS have been recognized by ICAO and the contracting states as the sole international regulations for reduction of aviation emission, the SARPs are also known to have some limitations on reduction of aviation emission. This paper therefore examines the capacity of SARPs Annex 16 Vol II of Chicago Convention 1944 to make effective reduction in international reduction of aviation emission for protection of environment. This involves identifying the strength and limitations of ICAO SARPs on reduction of aviation emission as well as making recommendations for improved performance. A qualitative-doctrinal research approach is adopted where by the bulk of analysis on the study is based on information from library research materials The study concludes the ICAO SARPs have more limitations than strength and would require some improvement for achieving a more effective reduction in aviation emission.
\end{abstract}

Key words: Rethinking, Potency, SARPs Annex16 Vol. II, Reduction, Civil Aviation Emission

\section{INTRODUCTION}

The ICAO's Standard And Recommended Practices (SARPs) ${ }^{2}$ are established and adopted by the International Civil Aviation Organization (ICAO), for the purpose of regulating aircraft emission in the aviation sector. These standards and Recommended practices are contained in Annex 16 Vol II of Chicago convention 1944. The creation of ICAO standards and Practices on aviation environment came up in 1981, due to the declaration in Article 2(2) ${ }^{3}$ of Kyoto protocol to UNFCCC 1997, that developed countries of (Annex I parties), shall pursue limitation or reduction of emission of

\footnotetext{
Article 2 (2) of Kyoto Protocol delegates responsibility for reduction of greenhouse gases in the aviation sector to ICAO.

SARPs Annex 16 Vol. II of Chicago Convention 1944, are the standard and recommended practices on aviation environment.

3 Article 2 (2) of Kyoto Protocol delegates responsibility for reduction of greenhouse gases in the aviation sector to ICAO.
} 
greenhouse gases from aviation by working through the international civil aviation organization (ICAO). Subsequent to this directive, the responsibilities for making and adoption of standards and recommended practices for control of aviation emission became a mandatory function for ICAO.

The Chicago Convention is the legal instrument that established ICAO. The Chicago convention came into existence in 1944. Since its creation, it has continued to serve as the body of rules which provided ICAO with the power to make standard and recommended practices to regulate aviation emission in the civil aviation sector. However, it shall be known that there was no mention of environmental protection as a mandate area for ICAO in the Chicago convention until $1981,{ }^{4}$ but the continued growth of the aviation industry and the demand for sustainable aviation development necessitated the need for ICAO to provide environmental Standard for aviation industry.

The process of creating SARPs involves a continuous and periodic review of the proposed standards and practices by states and members of the aviation industry as well as the committee on aviation environment protection (CEAP) which exists under ICAO. The considered standards are then passed to ICAO council which also adapts them inform of resolutions. These resolutions finally become Annexes of the standards in Annex 16 volume II of Chicago convention. Accordingly, all member states are therefore expected to follow and enforce the standards domestically and this is usually done through the process of domestication into national legislation by member states. However, it is relevant to mention that ICAO Assembly achieves its work through the effort and committee on Aviation Environmental protection (CAEP).

Article 37 of Chicago convention is the authority bestowed on ICAO to produce standards and practices for all parties participating in aviation activities. The Article provides that ICAO should work in line with the changes in aviation industry, to ensure an up to date work and procedure that promotes change driven standards. The article states: "Adoption of international standards and procedure. Each contracting state under takes to collaborate in securing the highest practicable degree of uniformity in regulations, standards, procedures and organization in relation to aircraft, personnel, air ways and anxiliary services in all matters in which such uniformity will facilitate and improve aviation and its activities. To this end, ICAO shall adopt and amend from time to time as may be necessary, international standards and recommended practices and procedures". ${ }^{5}$

The above article clearly states the responsibility of ICAO on international civil aviation. However, the next article in the convention Article 38 is relevant to be read along with article 37 in the sense that it shows the limit of the power of ICAO on mandatory enforcement of SARPs by ICAO members states. Articles 38 states: "Any state which finds it impracticable to comply in all respect with any such international standard or procedure or bring its own regulations or practices into full accord with any international standard or procedure after amendment of the latter or which deems it necessary to adopt regulations or practices differing in any particular respect from those established by international standard, shall give immediate notification to the international civil aviation organization of the differences between its own practice and that established by the international standard. In the case of amendment to international standard, any state which does not make the

See Heather L. Miller, n. 4 at 26.

See Article 37, Chicago Convention 1944 on the responsibilities of ICAO. According to Chicago Convention Article 37, ICAO the power and the legal basis for the adoption of amendment of international Standards and recommended practices and procedures (SARPs) are established by the council and promulgated as annexes to the Chicago Convention. For example, circumventing the formal treaty process and the need to amend the instrument of the organization. Traditionally, the legislative function of ICAO has been confined to the task of dealing with very technical issues with little room for political disagreement. See BUERGENTHAL, T. Law Making in the International Civil Aviation Organization, p. 62. 
appropriate amendments to its own regulations or practices shall give notice to the council within sixty days of the adoption of the amendment to the international standard, or indicate the action which it proposes to take. In any such case, the council shall make immediate notification to all other states of the differences which exists between one or more features of an international standard and the corresponding national practice of that state"6.

In essence, what can be understood from the provisions of article 37 and Article 38 above is that while Article 37 bestows on ICAO the power to ensure an update work on the changes in aviation industry and ensure each contracting State observes conformity with the standard on improvement on aviation activities, article 38 limits the mandatory enforcement of standard practices by contracting states. Also none of the provisions of this article mentioned everything regarding reduction of aviation emission.

Also the procedure for implementation of SARPs entails that all contracting states of the Chicago convention are required to implement SARPs in their different countries at the national level by bringing national regulations and practices into full accord with SARPs. However, it is expected that states who find it difficult to comply with SARPs and those who find it necessary to adopt regulation or practice different from that of SARPs should notify ICAO within the approved time frame. ICAO adopted a resolution at its 32 ordinary session in 1998 which led to the establishment of Universal Safety Oversight Audit Programme (USOAP). ${ }^{7}$ The aim for establishing (USOAP) was to promote national implementation of SARPs among contracting states. The USOAP Audit programme entails regular mandatory harmonized safety audit to be carried out on contracting states it came into effect in 1999 and at the $2^{\text {nd }}$ of that year about 49 states led been audited through the process of seeking cooperation of the contracting states and paying respects to the sovereignty of each contracting state. ${ }^{8}$ Therefore, the objectives of this paper are to assess the capability of SARPs for reduction of aviation emission, to identify its limitations and make necessary suggestions for improvement.

\section{ANALYSIS OF SARPS ANNEX 16 VOL. II ON REDUCTION OF AVIATION EMISSION}

The substantive provisions of ICAO standard and recommended practices are contained in Annex 16 vol. 2 of Chicago convention. By definition, the international standards are referred to as any specification for political characteristics, configuration, material performance, personnel or procedure which its uniform application in recognized for safety of international air navigation and for which member states are to comply in accordance with convention and where notification of the lying states. ${ }^{9}$ The recommended practices on the other hand, are referred to as any specification for physical characteristics, configuration, material performance, personnel or procedure which

6 Convention on International Civil Aviation, (Doc 7300/9) www.icao.int/publications/pages/doc7300.espx Accessed 22 August 2015. Also see Article 38 Chicago Convention on limitation of mandatory enforcement of standard practices among contracting states.

7 ICAO establishment of an ICAO Universal Safety Oversight Audit Programme, Assembly Resolution A32-11 at 32 session of the Assembly.

8 ICAO milestone achievement of 1999 emphasized safety and security of Global Air Transportation. News released at p10, 19/19 icao website on line http://www.icao.int/icao/en/1999 accessed 7/5/15.

9 See part 1, Standard And Recommended Practices (SARPs) Annex 16 vol. II. 
its uniform application is organized as desirable in the interest of safety regulations or efficiency of international air navigation and to which member state shall conform in accordance with the convention the simple understanding of the definitions above, is that both the international standards and recommended practices are not binding but notification of difference in respect of standards is compulsory for noncomplying states. Also, recommended practices have no obligation on notification of differences and are considered advisory in nature. ${ }^{10}$

From the above, the substantive provisions of SARPs of Annex 16 vol. II. Of Chicago convention, are the standards for control of smoke and gaseous emission from aircraft from international civil aviation. These also include standard on aircraft engine certification and standard for international fuel venting involving international discharge in to the air of liquid fuel nozzle manifold of aircraft during engine shut down in normal flight or ground operations. The main objectives of this annex $16 \mathrm{Vol}$ II (SARPs) is to achieve reduction in the level of aviation emission pollutants from air craft engine. ${ }^{11}$

A careful study of Annex $16 \mathrm{vol}$. II on ICAO SARPs shows that it is organized into three parts. Part 1 contains definitions and symbols used and meaning ascribed to these definitions. Meanwhile, the definition of Standards and recommended Practices has been given above. Part II contains standard on vented fuel while part III contains standard on smoke and gaseous emission certification which apply to different classes of aircraft engines that are fitted to aircraft civil aviation.

The Standard Relating to Vented Fuel ${ }^{12}$ is one of the prominent standards of Annex 16 Vol.II. The above provision which is contained in part II SARPs Annex $16 \mathrm{Vol}$ II applies to all turbine engine powered aircraft intended for international navigation that are manufactured after $18^{\text {th }}$ February 1982. According to this part, the certification for prevention of international fuel venting shall be granted by relevant authority based on satisfactory evidence that the aircraft or the aircraft engine complies with the requirements of this part. However, a note on the recommended practices is also written on the requirement on part II. The recommended practices state that documents attesting certification on fuel venting may take the form of certification or a statement contained in another documents approved by the certificating authority. Further, contracting states shall recognize as a valid certificating, a certification on fuel venting granted by another contracting state provided the requirement for granting the certification was not less stringent then the provision of volume II of this annex. ${ }^{13}$

However, it is observed that the above contains no provisions stipulating any avenue for accepting a contracting state that has been granted a certification by another contracting state under less stringent condition than those contained in the annex.

It is also observed that part II of the annex that required manufacturer of aircraft engine to prove to the certification authority with satisfactory evidence that his product satisfies the emissions and fuel venting standard and safety standard is inadequate. Although the above standard is applicable to aircraft manufactured after 1982, the fact that considerable number of commercial aircraft in service are manufactured before 1982 shows that the standards contained in part II of annex 16 can only succeed in control of fuel venting partially further it is observed that this provision contains no statement on whether or not the certification is subject to expiry and renewal.

10 Also, see SARPs above on definition of recommended practices.

11 See ICAO Assembly resolution in force at $5^{\text {th }}$ oct.2001 in ICAO document 9790.

12 See part II, of SARPs, Annex 16 vol. II.

13 See part II chapter 1.3 of SARPs Anne 16 vol. II. 
The standard on Smoke and Gaseous Emission ${ }^{14}$ is next to the above. The standard relating to control of aviation emissions certification is contained in part III Annex 16. This requires certification of aircraft engine and not the aircraft. Just like in the case of standard on vented fuel the certification authority for engine or equivalent procedure shad been carried out, national certification will be exempted the standards on smoke are made inform of regulating smoke number and apply to turbo engine and turbo fan engine manufactured on or after Jan 1993. The gaseous emission standards for $\mathrm{HC}$ and $\mathrm{CO}$ are applicable to engine with rated output is greater the $26.7 \mathrm{KN}$ and while date of manufacture is on or after $1986 .{ }^{15}$ Engine can be certified during test unless they meet with the above regulatory standard which the above regulatory standard which expressed inform of regulatory level

As regards emission limits for next (oxides of Nitrogen) three level of stringency of regulatory level are prescribed by standard. The first level of stringency which is least straight is for engine model manufactured on or before 31 Dec. 1995 or for which the date of manufacture of the model engine was or before 31 Jan 1999. ${ }^{16}$ The most level of stringency test applies to engines or model for which management for individual production was after Dec 1999 for date of manufacture of individual engine. The third level of stringency applies to engine or model which production of the first individual production was $31^{\text {st }}$ Dec. 2003. Engine with higher rated thrust pressure are acted to most stringency standard engine for international air navigation must its emission of its Nitrogen Oxides when measured and tested, must meet up with recommended and required standard before it can be certified.

However, different standards are recommended for aircraft engine intended for propulsion at subsonic speeds and supersonic speeds. ${ }^{17}$ In both cases, engine shall be tested according to specified reference landing and take-off LTO cycles. The emission measured and reported with the specified standard. The emission to be controlled is smoke and gaseous emissions which in a generic term comprises of Hydro Carbon (HC), Carbon Monoxide (Co) and Oxides of Nitrogen (NOx). The shortcoming of the above standards is that since the standards are designed to deal with the problem of air quality control within the airport vicinity and since this standard is recommended for emission within LTO $^{18}$ circle below 915 metres (30oo feet), the certification standards do not include other flight regime at climb and cruise level. ${ }^{19}$

Engine Intended for Supersonic Propulsion is another standard..$^{20}$ This standard for supersonic propulsion apply to all turbo jet and turbo fan engines manufactured before or after Feb. 1982. Emission of Hydro carbon (HC), Carbon monoxide (CO) and Oxides of Nitrogen (NOx) measured and reported must conform with the standard before certification can be granted. However, only one level of stringency is available as no emission will be determined for this after burning can be allowed by the certificating authority using the inference LTO cycle and the fact that the validity of such data provided is adequately demonstrated.

All Engines Intended for Subsonic Propulsion ${ }^{21}$ also represents a standard. The standard for engine certification in this category, is applicable to all turbo jet and turbo fan engines and other

14 See SARPs part III Annex 16 Vol. II, Chicago Convention.

15 Part III SARPS Annex 16 vol. II.

16 Ibid.

17 See part III chapt $1 \& 2$ of SARPs Annex 16 Vol. II.

18 The reference emission Landing and Take Off (LTO) cycle consists of: Climb, Approach and Taxi/ground idle see part III.

19 See CRASTON, J. Civil Aviation and The Environment, p. 16.

20 See SARPs part III, chpt 2. 1.

21 See part III, Chpt.4.2 SARPs Annex 16 Vol. II. 
engines designed for certification. The standard on smoke on turbo jets and turbo fans only apply to aircraft manufactured before $1^{\text {st }}$ Jan 1983 while those aircraft before 1965 are exempted from certification. It is also noted that all turbo jets and turbo fan engines including other engines designed for application are to meet up with the required standards before being approved for certification.

As part of recent development, it is observed that a new provision on aircraft carbon dioxide (CO2) emissions Standard will soon be added to the existing SARPs Annex 16.This new volume which will be known as volume III. ${ }^{22}$ A Carbon dioxide metric system with $\mathrm{CO} 2$ emissions for aircraft types with different technologies which had earlier been recommended upon by the Committee on Aviation Environmental Protection (CAEP) on 10 July 2012 was finally endorsed in 2013, while agreement on its certification procedure was equally reached. ${ }^{23}$ Following a unanimous agreement by 170 international experts of CAEP on February 2016, a new aircraft CO2 emission Standard was ultimately adopted by the ICAO Council. ${ }^{24}$

\section{THE PROBLEMS OF SARPS ANNEX 16 VOL. II ON REDUCTION OF AVIATION EMISSION}

A critical look at the performance of SARPs, shows that SARPs have maintained standard in the aviation industry. The standards put in place are referred to as models which applied to many states if not all. There has also been partial implementation of SARPs among large economic group and richer nations in the EU, North America, Australia etc. ${ }^{25}$ However, it is observed that despite the above contributions, the provisions of SARPs are not adequate for effective reduction of aviation emission. It is observed that SARPs have problems that militate against effective reduction in aviation emission. The following therefore, are therefore identified as the problems of SARPs on reduction of aviation emissions:

A careful examination of part two of Annex 16 vol. II shows that the provision in this part of the Annex is more or less put in place to address facilitation of orderly air traffic growth rather than show concern for climate change. This same lack of concern to address reduction in aviation emissions is also reflected in Article $37^{26}$ of Chicago convention on the creation of SARPs. Article 37 vests ICAO with original authority to adopt and amend SARPs in dealing with issues concerning airports and landing areas, rule of air and air control practices, worthiness of aircraft custom and immigration procedures, aircraft in distress and investigating accident while it said nothing about reduction of aviation emissions. By simple interpretation, the above shows that SARPs are originally intended to cater for growing needs of civil aviation and was limited to safety and efficiency of air navigation

22 See HOPE, J. Aviation and Environment Development since the Last Assembly (Unpublished Presentation delivered at the ICAO symposium on Aviation and Climate Change,' Destination Green”, Montreal 14 - 16 May 2013). See also Md Janveer Ahmad "Global Civil Aviation Emission Standards-From Noise to Green Fuels;, Ocassional paper Series No 25, 2016, Sustainable International Civil AViatio, Centre for Research and airspace law, MC Gill University, Canada, 2016.

23 See Pres release by ICAO, Com 15/12 “ New Progress on Aircraft C02 Standard:, accessed 11july 20i6 www.ICAO.int/ newsroom/pages/new progress-on-aircraft-CO2-standard.aspx.

24 See Hupe, Aviation and Environment Development Since the last Assembly, 37.

25 See Allen P. Jan and Annie Petsonk, n. 74 at 65. Also see Beatrix Martinez and HarrqVan Asselt.

26 Article 37 n. 112. Also see ICAO Definition of "International Standards and Recommended Practices Assembly ResolutionA1-31. ICAO doc. 4411 (Assembly Resolution A1-31. SeeThomas Beurgenthal, Law Making in the international civil Aviation Organization (New York Syracuse UniversityPress1969), 60. 
rather than cater for aviation emission. ${ }^{27}$ Although it is true that Annex 16 vol. 2 of Chicago convention was tagged Environmental protection Standards for preventing international fuel venting or international pollution through aircraft engine certification, the practice of preventing international venting fuel and aircraft pollution through engine certification is actually a regulatory activity carried out within the scope of aviation safety. The understanding of part II of Annex 16 II looks like environmental protection was squeezed into broader interpretation of the safety of air navigation, there was no specific power, or duty or clear cut intention to address environmental protection in the SARPs. Going by the above, ICAO SARPs on aircraft emission have problem in combating reduction in aviation emission related climate change.

Also, following a close examination of the SARPs, it is observed that part III of Annex16 vol. II focused on aircraft engine certification but not on the certification of aircraft. It is important to know that certifying aircraft engine alone is not sufficient for controlling emissions because this is just a part of the whole aircraft design. It may be sufficient in term of fuel efficiency but not in term of weight and suitability of aircraft. The certification of aircraft as a whole appears to make more sense rather than only its engine from environmental perspective. ${ }^{28}$ Although the present system of certifying aircraft engine in relation to emission is reasonable, there is need to consider other factors like aircraft weight in order to have a complete aviation emission control. ${ }^{29}$ Therefore with absence of concern for other parts of aircraft design, the ICAO SARPs in Annex 16 vol. II cannot totally control aviation emission.

It is further observed that ICAO standards as contained in Annex 16vol.II of Chicago convention are inadequate because the ICAO Standards only laid down standards with respect to discharge of emissions like hydrocarbons, carbon monoxide and Nitrogen oxide, while real implementation is yet to resume on the standards to cover carbon dioxide which is the major man made cause of global warming. ${ }^{30}$ This inadequacy in the provisions of ICAO Standards thus made it difficult for effective reduction in aviation emission

It has been found that ICAO SARPs do not have the power of enforcement and compliance. This can be explained in the sense that members states of ICAO who fail to implement the provisions of ICAO Standards are required to give notice to ICAO but shall incur no penalty for refusal to comply. The above weakness is further reinforced by the fact that while states may invoke dispute settlement provision over disagreement between states on application of ICAO Standard, the Chicago convention is silent on what action to be taken over a state that doesn't comply after giving notice to the ICAO. ${ }^{31}$ While it is true that some over sight powers were given to ICAO to regulate aviation emission under Annex 16 of Chicago Convention vol. II, it is discovered that this power did not give room for exclusive control, as member states of ICAO to a large extent remain free within the provisions of "Opt Out" rule of SARPs decide not to work with the provisions of SARPs but developed a consensual treaty based approach to carbon emission reduction without any penalty. A case in point is that of EU states acting through the EU Commission, unilaterally imposed carbon trading system on

27 See LIU, J. The Role of ICAO in Regulating Greenhouse Gas Emission from Aircraft, Carbon and Climate Change. In Carbon and Climate Change Law Review, p. 420. Also see SARAO, E. J. Global Versus Unilateral Measures to protect the World's Environment: Implications for the Air Transport Industry. In Journal of Air and Space, p. 51.

28 Paul S. Dempsey, n. 5 at 54.

29 Ibid.

30 Brian F. Havel and Gabriel Sanchez, n. 22 at 360.

31 CHARNEY, J.L. From Commitment and Compliance, The Role of Nonbinding Norms. In SHELTON, D. (ed.) Compliance with International Soft Law, p. 15. 
all airliners, regardless of national origin while the air liners operated at the airports within the EU territory. ${ }^{32}$ Failure of SARPs to ensure enforcement and compliance to standards shows that SARPs were weak laws that are not effective for reduction of aviation emission.

It has been reported that the environmental protection measures adopted under Annex 16 vol. II of Chicago convention are only geared towards the narrow objective of reducing the level of pollutants from aircraft engine instead of broad goal of environmental sustainability. The reason for this is because it has been difficult to get a suitable medium for addressing the assimilative capacity of the environment in relation to aircraft engine emission, particularly, when the level of uncertainty surrounding the atmospheric effect of aircraft engine emission and the processes that take place at altitude are considered. ${ }^{33}$ Therefore, it has been concluded that all regulatory measures of SARPs that were used in the absence of a suitable medium for determining assimilative capacity of the environment were only directed towards reduction of aircraft emission at a shallow level and thus not effective for broad goal of environmental sustainability.

It has also been reported that one of the reasons for ineffective reduction of aviation emission by SARPs is the limitations to assumptions on aircraft engine certification. The scheme for certification of aircraft engine on international fuel venting, smoke and gaseous emission as of Annex 16 vol. II, can be said to be highly characterized as a preventive measure designed to have good effect on reduction of aviation emission in the sense that it was based on the assumption that the quantity of pollutant from global aviation emission sector can be dumped into the atmosphere without exceeding its assimilative capacity is known or can be estimated and that the level prescribed by standard bear close relationship to those values ${ }^{34}$ In reality, the assumption about notification scheme is that the scheme lacks required variables like the total number of aircraft and engines engaging in international air navigation which have to be regulated as well. ${ }^{35}$ Assuming the assimilative capacity of the environment in term of knowing the quantity of pollutant that can be safely absorbed by the environment without causing a permanent damage is known or be estimated. Achieving optimal environmental result from certification of aircraft engines will be difficult since there are no limits on the number of air craft or engine that may be certified by relevant certification authority of each contracting states under the annex. In addition to this preventive measure acting by itself are not always enough for purpose of controlling pollution. ${ }^{36}$ Despite operation of the certification scheme since1981, there are still complaint of increasing volume of aviation emission. Therefore, there is need for a more effective measure to complement the certification scheme. It is believed employing other measures like emission Trading will improve reliance on this preventive measure.

It has further been observed that ICAO SARPs rules are asset of soft law that lack power of compliance on members. This is because the "Opt Out" rule present in the SARPs disempowered the convention from enforcing the SARPs on contracting states, thereby permitting noncompliance with

32 Ibid.

33 Paul S. Dempsey, n. 5 at 637 Also see David S Lee, Aviation and Climate Change, n. 1, 30.

34 Bin Cheng, n. 91 at 65.

35 CHARNEY, J.L. From Commitment and Compliance, The Role of Nonbinding Norms. In SHELTON, D. (ed.) Compliance with International Soft Law, p. 17.

36 Ruwantissa Abeyratne. The Legal effects of ICAO's Decision and Empowerment of ICAO by Contracting States. Annual Review of Air and Space Law, Vol. 32/2009, p. 58. Also note that ICAO Resolution A35-5 Consolidated statement of Continuing ICAO's policies and Practice related to environmental protection 2004. Appendix A and I of ICAO Assembly Resolution have been classified as soft law or quasi law for this purpose. This goes to show that even though the laws are not legally binding, contracting states are expected to follow them unless they express reservation. See Brian Havel And Gabriel Sanchez, The principles and Practice of International Law (CUP 2004), 60. 
the standards and practices on reduction of aviation emission. The primary attributes that would have made SARPs hard law and ensure compliance were non-existent. ${ }^{37}$ Therefore, the prevalence of soft law in SARPs accounts for the ineffectiveness in reduction of aviation emission.

\section{CONCLUSION}

The paper discussed the Standard And Recommended practices (SARPs) Annex 16 Vol. II of Chicago Convention as the law approved for reduction of aviation emission by ICAO. The content of SARPs Annex 16 Vol. II has been analysed and it is found that Part II contains no provision which allows a contracting state to be granted a certification by another contracting state unless under a stringent condition similar to ICAO. It is also observed that Part II of SARPs which requires certification on fuel emission, fuel venting standard and safety standards by aircraft manufacturers is not adequate. There is also no provision on whether or not the certification on the above standards is subject to expiration or renewal. Other problems of SARPs Annex 16 Vol. II are found to include lack of concern for Climate Change while the engine certification lack consideration for aircraft. The SARPs do not cover carbon dioxide emission and also lack the capacity for enforcement and compliance. SARPS are found to have no definite objective while the engine certification lacks required variables.

Since it has been observed that the existing ICAO Civil Aviation Emission Standards and Practices are not potent for effecting adequate reduction in aviation emission and for enhancing sustainable aviation environment, the following are therefore recommended for improving the deficient condition. The SARPs Annex 16 Vol. II of Chicago Convention 1944, should be amended to include provisions for control of all necessary greenhouse gases and other modern innovations that could enhance its effectiveness on reduction of aviation emission. To this end, the emission standards should be upgraded to cover carbon dioxide emission and water vapour. Also, the Global Market Based Measures (MBM) for reduction of aviation emission such as Global Aviation Emission Trading should be implemented to serve as additional supporting measure to the existing regulations of SARPS. Further, the ICAO law making body and the ICAO Committee on Aviation Environmental Protection (CAEP) should dissuade themselves from embarking on decisions and actions that will always encourage the growth of aviation emission. ICAO should accord commitment and seriousness to giving approval to implementation of its regulations and standards by member states. It is further recommended that SARPs should be transformed to a hard law and provided with full power for enforcement and compliance on contracting states. The engine certification standards should be reviewed to have the required technical variables and also have full consideration for aircraft.

\section{Bibliogprahy:}

CHARNEY, J.L. From Commitment and Compliance, The Role of Nonbinding Norms. In SHELTON, D. (ed.) Compliance with International Soft Law. Oxford University Press, 2000.

CRASTON, J. Civil Aviation and The Environment. UNEP. Industry and Environment publication, 1993.

37 Peter D.C and Donald, Z. Kyoto: From Principles to Practice, Kluver Law International, 2001, p. 11. 
BUERGENTHAL, T. Law Making in the International Civil Aviation Organization. $1^{\text {st }}$ edition. Syracuse University Press, 1989.

PEI JAN, A. - PETSONK, A. The Skies, An Airline Based System for Limiting Greenhouse Gas Emission from International Civil Aviation, Environmental Lawyer, Vol. 76, 2000.

MARTINEZ, M. - VAN ASSELT, H. International Regulation of Aviation Emission, Putting Differential Treatment into Practice. In Oxford Journal of Environmental Law, 27, Vol. 3, 2015.

LIU, J. The Role of ICAO in Regulating Greenhouse Gas Emission from Aircraft, Carbon and Climate Change. In Carbon and Climate Change Law Review. Vol. 5. no. 4/2011.

SARAO, E. J. Global Versus Unilateral Measures to protect the World's Environment : Implications for the Air Transport Industry. In Journal of Air and Space Vol. 27/2002, 51.

VANDAM R.D. Regulating Aviation: An ICAO perspective. In TANJAH M.L. - ZWA, P. - MENDES LEONE, M.J. (eds.) ICAO at the beginning of $21^{\text {st }}$ century, Air Space Law, Vol. 313/2008, 53.

Convention on International Civil Aviation (Chicago Convention 1944), (Doc 7300/9).

ICAO establishment of an ICAO Universal Safety Oversight Audit Programme, Assembly Resolution A32 11 at 32 session of the Assembly.

Kyoto Protocol to the United Nations Framework Convention on Climate Change (UNFCCC) 1997,

Standard And Recommended Practices (SARPs) Annex 16 vol. II, of the Convention on International Civil Aviation (Chicago Convention), 1944.

\section{Contact information:}

Dr. Murtala Ganiyu A Murgan

University of Ilorin, Faculty of Law

1515, Unilorin Staff Quarters, Amodu Bello Way

Ilorin

Nigeria

prof. Dr. Abdul Ghafur Hamid

International Islamic University, Ahmad Ibrahim Kulliyyah of Laws

50728 Kuala Lumpur

P. O. Box 10

Malaysia

Assoc. Prof. Maizatun Mustapha

maizatun@iium.edu.my

International Islamic University, Ahmad Ibrahim Kulliyyah of Laws

50728 Kuala Lumpur

P. O. Box 10

Malaysia 